\title{
Applicability of Messenger Wire for Purpose of Lightning Protection
}

\author{
Hun-Chul Seo*, Joon-Han**, Sun-Kyu Choi***, Byung-Sung Lee ${ }^{* * *}$, Sang-Bong Rhee ${ }^{\S}$ \\ and Chul-Hwan Kim ${ }^{\dagger}$
}

\begin{abstract}
The Korean distribution line currently consists of overhead ground wires (OHGW), overhead distribution lines, neutral wires (NW), and messenger wires (MW). The MW is installed under the NW. The lightning protection system in Korea is focused on OHGW and lightning arrester and the MW are not considered. Therefore, this paper proposes the applicability of MW for purpose of lightning protection. For this, we analyzed the effects of lightning overvoltage according to the existence of OHGW and MW and the grounding conditions of the MW in the Korean distribution system. The grounding conditions of the MW that we took into consideration were the common or separate grounding of the MW and NW. The analysis based on the equivalent circuit of the distribution pole at each condition was performed. The distribution lines and lightning were modeled using the Electromagnetic Transients Program (EMTP). For each of the installation conditions of the OHGW and MW, the various lightning conditions were simulated and analyzed for both direct and indirect lightning. The simulation results showed that, if the OHGW was not installed in the Korean distribution system, the lightning overvoltage could be reduced by the common grounding of the MW and NW.
\end{abstract}

Keywords: Direct lightning, Indirect lightning, Overhead ground wires, Lightning overvoltage, Neutral wires, Messenger wires

\section{Introduction}

The Korea Electric Power Corporation (KEPCO) distribution system uses 22.9 [kV] Y-connected, three-phase, four-wire, high-tension lines. Fig. 1 shows the structures of one-step type (single circuit pole) and two-step type poles (double circuit pole) [1]. As shown in Fig. 1, the distribution line consists of the overhead ground wire (OHGW), overhead distribution line, neutral wire (NW), and messenger wire (MW). The MW is a wire or cable that is used solely for the physical support of another element, typically communication wire in KEPCO's distribution line. The MW is installed under the NW.

Lightning may cause flashovers on the distribution lines from both direct strikes and the induced voltage from nearby strikes. Direct lightning strikes to distribution lines mostly cause flashovers. Lightning-induced voltages are a major issue for the electromagnetic compatibility and power quality due to the widespread use of sensitive devices connected to the distribution lines. The lightning

$\dagger \quad$ Corresponding Author: College of Information and Communication Engineering, Sungkyunkwan University, Korea.

(hmwkim@hanmail.net)

* School of IT Engineering, Yonam Institue of Digital Technolgy, Korea. (hunchul12@yc.ac.kr)

** College of Information and Communication Engineering, Sungkyunkwan University, Korea. (j3angh@gmail.com)

*** Power System Laboratory, KEPRI, Korea (skchoi@kepco.co.kr, leebs@kepri.re.kr)

$\S$ Department of Electrical Engineering, Yeungnam University, Korea (rrsd@yu.ac.kr)

Received: December 2, 2014; Accepted: July 31, 2015

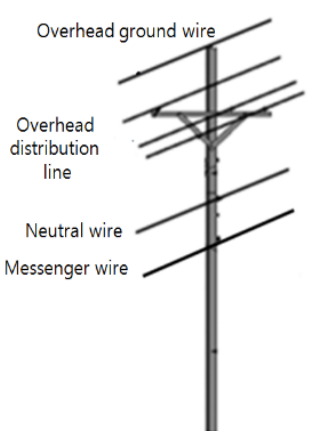

(a) one step type pole

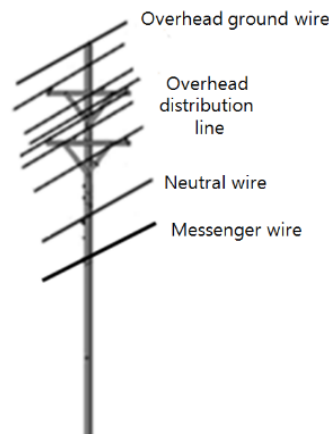

(b) two step type pole
Fig. 1. Structural diagram of pole types

performance for lightning protection has been studied by many researchers [2-9]. These are mainly focused on the calculation of overvoltage or flashover rate at various configurations of lightning protection system, such as ground wire, lightning arrester, grounding resistance, and etc. However, the previous study considering the existence of MW under NW has not been performed.

The Korean distribution line includes various types of equipment, such as the $\mathrm{OHGW}$ and lightning arrester, to protect against lightning. However, the lightning protection system of Korea does not take into consideration the existence of MW under NW.

Therefore, this paper proposes the applicability of MW for purpose of lightning protection. To verify the applicability of MW, we analyzed the effects of lightning overvoltage according to the installation conditions of the 
OHGW and MW in the Korean distribution system. The conditions taken into consideration were the existence of the OHGW and MW as well as the common or separate grounding of the MW and NW. In Section 2, when the MW is considered for lightning protection, the equivalent circuit analysis was performed to describe the differences between the common and separate grounding of the MW and NW. The modeling of distribution line and lightning using the Electromagnetic Transients Program (EMTP) is discussed in Section 3. In Section 4, the simulation of the various lightning magnitudes, ground resistivity, and lightning locations for each installation condition of the OHGW and MW for both direct and indirect lightning is discussed. Based on the simulation results, the lightning overvoltage according to the installation conditions of the OHGW and MW was analyzed. Finally, the conclusions are discussed.

\section{Theoretical Analysis of Lightning Overvoltage Considering MW}

The previous study to consider the MW for lightning protection has not been performed. Therefore, firstly, to discuss the applicability as a new purpose of MW, a theoretical analysis to calculate the lightning overvoltage is required.

This paper performs the theoretical analysis of overvoltage using equivalent circuit when both MW and NW exist. Specially, grounding conditions of the MW is discussed because the lightning overvoltage is affected from grounding conditions. We assume that first reflection wave is only considered because the magnitude of surge is damped by resistance of line as time elapses and the mutual coupling between two wires is neglected.

Fig. 2 shows the equivalent circuit of the distribution pole when the common grounding of MW and NW was used. The meaning of each parameter used in Fig. 2 is presented in Table 1.

The phase conductor to the neutral wire voltage, $\mathrm{V}_{\text {com }}$, can be written as follows:

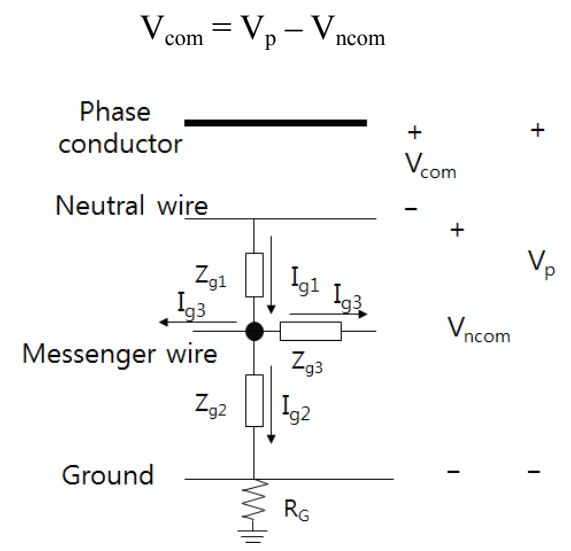

Fig. 2. Equivalent circuit when the messenger wire and neutral wire were commonly grounded
Table 1. Meaning of each parameter in Fig. 2

\begin{tabular}{c|l}
\hline Parameter & \multicolumn{1}{c}{ Meaning } \\
\hline $\mathrm{V}_{\text {com }}$ & Phase conductor to neutral wire voltage \\
\hline $\mathrm{V}_{\mathrm{ncom}}$ & Neutral wire to ground voltage \\
\hline $\mathrm{V}_{\mathrm{p}}$ & Phase conductor to ground voltage \\
\hline $\mathrm{I}_{\mathrm{g} 1}$ & Current flowing from neutral wire to messenger wire \\
\hline $\mathrm{I}_{\mathrm{g} 2}$ & Current flowing from messenger wire to ground \\
\hline $\mathrm{I}_{\mathrm{g} 3}$ & Current flowing in messenger wire \\
\hline $\mathrm{Z}_{\mathrm{g} 1}$ & $\begin{array}{l}\text { Impedance of down conductor between neutral wire } \\
\text { and messenger wire }\end{array}$ \\
\hline $\mathrm{Z}_{\mathrm{g} 2}$ & $\begin{array}{l}\text { Impedance of down conductor between messenger wire } \\
\text { and ground }\end{array}$ \\
\hline $\mathrm{Z}_{\mathrm{g} 3}$ & Impedance of messenger wire \\
\hline $\mathrm{R}_{\mathrm{G}}$ & Grounding resistance \\
\hline
\end{tabular}

In (1), $\mathrm{V}_{\text {ncom }}$ is the sum of the voltage drop between NW and MW and the voltage drop between MW and the ground, which can be written as follows:

$$
\begin{aligned}
\mathrm{v}_{\text {ncom }}= & \mathrm{I}_{\mathrm{g} 1} \mathrm{Z}_{\mathrm{g} 1}+\left(\frac{\mathrm{Z}_{\mathrm{g} 2}-\mathrm{Z}_{\mathrm{g} 1}}{\mathrm{Z}_{\mathrm{g} 2}+\mathrm{Z}_{\mathrm{g} 1}}\right) \mathrm{I}_{\mathrm{g} 1} \mathrm{Z}_{\mathrm{g} 1} \\
& +\mathrm{I}_{\mathrm{g} 2} \mathrm{Z}_{\mathrm{g} 2}+\left(\frac{\mathrm{R}_{\mathrm{G}}-\mathrm{Z}_{\mathrm{g} 2}}{\mathrm{R}_{\mathrm{G}}+\mathrm{Z}_{\mathrm{g} 2}}\right) \mathrm{I}_{\mathrm{g} 2} \mathrm{Z}_{\mathrm{g} 2}
\end{aligned}
$$

In (2), voltage drop considering reflection wave is calculated. If we apply Kirchhoff's current law at the common node of NW and $\mathrm{MW}$, then $\mathrm{I}_{\mathrm{g} 1}=\mathrm{I}_{\mathrm{g} 2}+2 \mathrm{I}_{\mathrm{g} 3}$ and, therefore, $\mathrm{I}_{\mathrm{g} 2}$, can be written as follows:

$$
\mathrm{I}_{\mathrm{g} 2}=\mathrm{I}_{\mathrm{g} 1}-2 \mathrm{I}_{\mathrm{g} 3}
$$

By substituting (3) to (2), $\mathrm{V}_{\text {ncom }}$ can be written as follows:

$$
\begin{aligned}
\mathrm{v}_{\text {ncom }}= & \mathrm{I}_{\mathrm{g} 1}\left(\mathrm{Z}_{\mathrm{g} 1}+\mathrm{Z}_{\mathrm{g} 2}\right)-2 \mathrm{I}_{\mathrm{g} 3} \mathrm{Z}_{\mathrm{g} 2}+\left(\frac{\mathrm{Z}_{\mathrm{g} 2}-\mathrm{Z}_{\mathrm{g} 1}}{\mathrm{Z}_{\mathrm{g} 2}+\mathrm{Z}_{\mathrm{g} 1}}\right) \mathrm{I}_{\mathrm{g} 1} \mathrm{Z}_{\mathrm{g} 1} \\
& +\left(\frac{\mathrm{R}_{\mathrm{G}}-\mathrm{Z}_{\mathrm{g} 2}}{\mathrm{R}_{\mathrm{G}}+\mathrm{Z}_{\mathrm{g} 2}}\right)\left(\mathrm{I}_{\mathrm{g} 1}-2 \mathrm{I}_{\mathrm{g} 3}\right) \mathrm{Z}_{\mathrm{g} 2}
\end{aligned}
$$

In the case of separate grounding, the phase conductor to the neutral wire voltage can be derived by equivalent

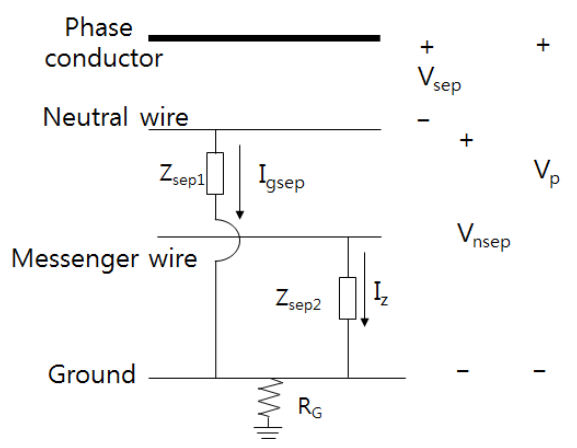

Fig. 3. Equivalent circuit when the messenger wire and neutral wire were grounded separately 
Table 2. Meaning of each parameter in Fig. 3

\begin{tabular}{c|l}
\hline Parameter & \multicolumn{1}{c}{ Meaning } \\
\hline $\mathrm{V}_{\text {sep }}$ & Phase conductor to neutral wire voltage \\
\hline $\mathrm{V}_{\text {nsep }}$ & Neutral wire to ground voltage \\
\hline $\mathrm{V}_{\mathrm{p}}$ & Phase conductor to ground voltage \\
\hline $\mathrm{I}_{\mathrm{gsep}}$ & Current flowing from neutral wire to ground \\
\hline $\mathrm{I}_{\mathrm{z}}$ & Current flowing from messenger wire to ground \\
\hline $\mathrm{Z}_{\text {sep1 }}$ & $\begin{array}{l}\text { Impedance of down conductor between neutral wire } \\
\text { and ground }\end{array}$ \\
\hline $\mathrm{Z}_{\text {sep2 }}$ & $\begin{array}{l}\text { Impedance of down conductor between messenger wire } \\
\text { and ground }\end{array}$ \\
\hline $\mathrm{R}_{\mathrm{G}}$ & Grounding resistance \\
\hline
\end{tabular}

analysis of the distribution pole. Fig. 3 shows the equivalent circuit of the distribution pole when the MW and NW were grounded separately. In addition, the meaning of each parameter in Fig. 3 is presented in Table 2.

Similar to (1), the phase conductor to neutral wire voltage $\mathrm{V}_{\text {sep }}$ can be written as follows:

$$
\mathrm{V}_{\mathrm{sep}}=\mathrm{V}_{\mathrm{p}}-\mathrm{V}_{\mathrm{nsep}}
$$

where $\mathrm{V}_{\text {nsep }}$ is the voltage drop between NW and the ground and can be written as:

$$
V_{\text {nsep }}=I_{\text {gsep }} Z_{\text {sep } 1}+\left(\frac{R_{G}-Z_{\text {sep } 1}}{R_{G}+Z_{\text {sep } 1}}\right) I_{\text {gsep }} Z_{\text {sep } 1}
$$

For comparison of (4) and (6), we need some assumptions. Regardless of the grounding of the MW and NW, the type and length of the down conductor were the same, as was the grounding resistance. Therefore, (7) can be derived from (4) and (6) as follows:

$$
\mathrm{Z}_{\mathrm{g} 1}+\mathrm{Z}_{\mathrm{g} 2}=\mathrm{Z}_{\mathrm{sep} 1}
$$

Also, when lightning occurred, the current toward the down conductor for grounding was the same and, therefore, (8) can be derived from (4) and (6) as follows:

$$
I_{g 1}=I_{g s e p}
$$

We can assume $Z_{\mathrm{g} 1} \fallingdotseq 0$ in (4) because the line length between NW and MW is much shorter than between MW and ground. This derives $\mathrm{Z}_{\mathrm{g} 2}=\mathrm{Z}_{\mathrm{sep} 1}$ from (7).

Then, if we apply above assumptions and then subtract (6) from (4), (9) can be derived

$$
\begin{aligned}
\mathrm{V}_{\text {ncom }}-\mathrm{V}_{\text {nsep }} & =-2 \mathrm{I}_{\mathrm{g} 3} \mathrm{Z}_{\mathrm{g} 2}-\left(\frac{\mathrm{R}_{\mathrm{G}}-\mathrm{Z}_{\mathrm{g} 2}}{\mathrm{R}_{\mathrm{G}}+\mathrm{Z}_{\mathrm{g} 2}}\right)\left(2 \mathrm{I}_{\mathrm{g} 3}\right) \mathrm{Z}_{\mathrm{g} 2} \\
& =-2 \mathrm{I}_{\mathrm{g} 3} \mathrm{Z}_{\mathrm{g} 2}\left(\frac{2 \mathrm{R}_{\mathrm{G}}}{\mathrm{R}_{\mathrm{G}}+\mathrm{Z}_{\mathrm{g} 2}}\right)<0
\end{aligned}
$$

In other words, the magnitude of $\mathrm{V}_{\text {ncom }}$ was smaller than $\mathrm{V}_{\text {nsep. }}$. Also, $\mathrm{V}_{\mathrm{p}}$ is smaller than $\mathrm{V}_{\text {ncom }}$ and $\mathrm{V}_{\text {nsep. }}$. Finally, we compared the absolute values of (1) and (5) as follows:

$$
\begin{gathered}
\left|\mathrm{V}_{\mathrm{p}}-\mathrm{V}_{\text {ncom }}\right|<\left|\mathrm{V}_{\mathrm{p}}-\mathrm{V}_{\text {nsep }}\right| \\
\left|\mathrm{V}_{\text {com }}\right|<\left|\mathrm{V}_{\text {sep }}\right|
\end{gathered}
$$

From (10), we can conclude that the overvoltage with the common grounding of MW and NW is smaller than that with separate grounding. This result means that the MW connected with common grounding with NW is applicable as new purpose for lightning protection.

\section{Modeling of Distribution Line and Lightning}

\subsection{Modeling of distribution line}

The modeling of the Korean distribution line using EMTP is discussed. Fig. 4 shows the configuration of pole in Korean distribution line. The geometrical arrangement of phase conductors, $\mathrm{OHGW}, \mathrm{NW}$, and $\mathrm{MW}$ is represented in Fig. 4. The meaning of number in brackets of Fig. 4 is the horizontal and vertical distance of wires from ground.

The types of overhead distribution line, OHGW, and NW modeled in this study were the Aluminum Conductor Steel-Reinforced (ACSR) $95\left[\mathrm{~mm}^{2}\right]$, WO $32\left[\mathrm{~mm}^{2}\right]$, and ACSR $60\left[\mathrm{~mm}^{2}\right]$, respectively. The type of MW was the FS $38\left[\mathrm{~mm}^{2}\right]$. The installation height of the MW was $10.5 \mathrm{~m}$ [10-11]. Fig. 5 shows the EMTP modeling of the distribution line not including the OHGW but including the MW.

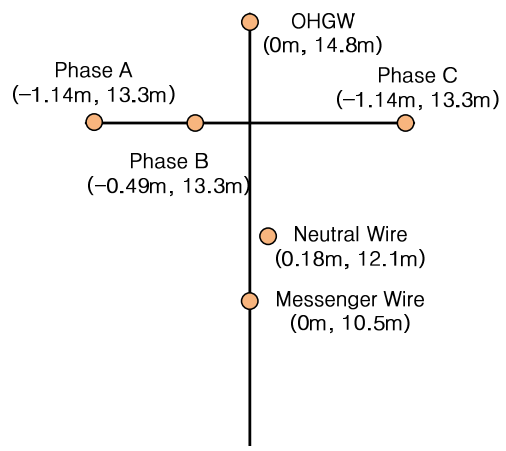

Fig. 4. Configuration of pole in Korean distribution line

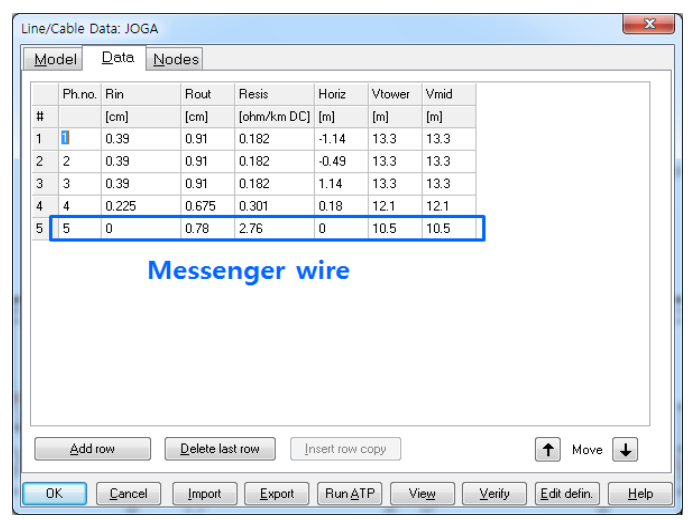

Fig. 5. Modeling of the distribution line using EMTP/ ATPDraw 


\subsection{Modeling of down conductor for grounding}

The down conductor for grounding was also modeled using the EMTP. It was modeled by the transmission line in order to take into consideration the propagation and reflection of the lightning current at the ground. The model was characterized by the characteristic impedances and propagation velocity. The following expression is introduced to represent the characteristic impedance of a vertical conductor [12-13]:

$$
Z=60 \ln \frac{h}{r}+90 \frac{r}{h}-60
$$

where $h$ is the height of the vertical conductor, and $r$ is the radius of the vertical conductor.

The type of down conductor modeled in this study was the OW $25\left[\mathrm{~mm}^{2}\right]$. In this type of conductor, $\mathrm{r}$ was 3.21 [mm] and $h$ was varied by the length of the down conductor. At each condition, the characteristic impedance was calculated using (10). The propagation velocity was considered as a light velocity.

For the case of direct lightning, the surge characteristics of the concrete pole were added. The radius and height of the concrete pole were $0.138 \mathrm{~m}$ and $13.5 \mathrm{~m}$, respectively. The surge impedance was calculated by (10). Also, the propagation velocity was inputted as the light velocity.

\subsection{Modeling of lightning arrester}

The modeling of lightning arrester using EMTP is discussed. The type of lightning arrester modeled is Gapless $\mathrm{ZnO}$ for distribution line. The rated and discharge voltage of $\mathrm{ZnO}$ lightning arrester for distribution line is $18[\mathrm{kV}]$ and below $66[\mathrm{kV}]$, respectively. The NLRES Type 92 component provided by EMTP is used to model the lightning arrester in this paper. Fig. 6 shows the input screen of $\mathrm{V}$-I characteristics of $\mathrm{ZnO}$ lightning arrester using EMTP.

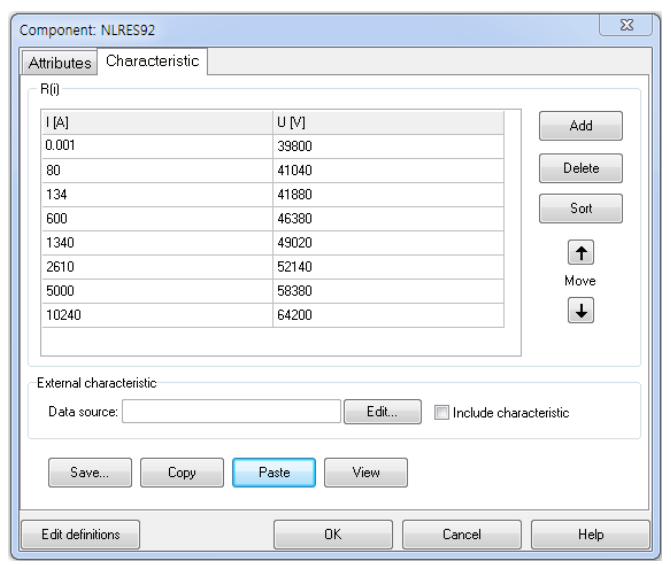

Fig. 6. Modeling of the lightning arrester using EMTP/ ATPDraw

\subsection{Modeling of direct and indirect lightning}

Direct and indirect lightning are classified by the striking distance based on IEEE Std. 1410 [14].

The waveform of direct lightning is modeled by EMTP/ MODELS based on the analytical formulation of the Heidler type [15]. The modeled waveform was $2 / 70[\mu \mathrm{s}]$ and was connected to the overhead ground wire or phase conductor by a type 60 TACS source in the EMTP.

There have been many studies conducted on the overvoltage due to indirect lightning $[2-8,16]$. This paper calculates the lightning-induced voltage on the overhead line using the method proposed by H. K. Hoidalen [16], which has been implemented using the EMTP/MODELS.

\section{Simulation and Discussion}

\subsection{Simulation model}

This paper models the standard distribution system with a total length of $2[\mathrm{~km}]$ in Korea as shown in Fig. 7. The spacing between the two adjacent groundings of the OHGW was $200[\mathrm{~m}]$, and the grounding resistance of the OHGW was $50[\Omega]$. A lightning arrester was installed every $500[\mathrm{~m}]$, and the grounding resistance of each lightning arrester was $25[\Omega]$. These values of interval and resistance are the standard value of KEPCO's distribution line in Korea. Some part of modeling of this standard distribution system using EMTP is represented in Fig. 8.

\subsection{Simulation conditions}

The lightning protection system in Korea does not

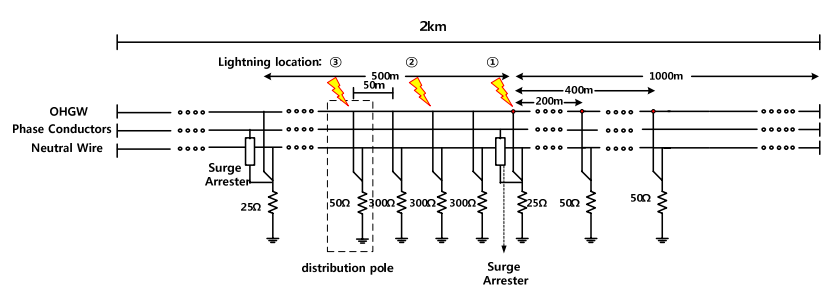

Fig. 7. Standard configuration of Korean distribution system

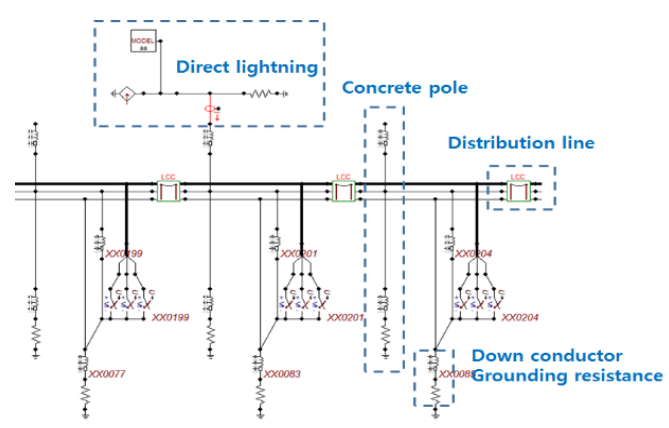

Fig. 8. Modeling of standard distribution system in Korea using EMTP 
Table 3. Simulation conditions

\begin{tabular}{c|l}
\hline Parameter & \multicolumn{1}{c}{ Meaning } \\
\hline Case & Installation conditions of OHGW and MW \\
\hline Case 1 & With OHGW / Without MW \\
\hline Case 2 & $\begin{array}{l}\text { With OHGW / With MW } \\
\text { (common grounding of MW and NW) }\end{array}$ \\
\hline Case 3 & $\begin{array}{l}\text { With OHGW / With MW } \\
\text { (separate grounding of MW and NW) }\end{array}$ \\
\hline Case 4 & Without OHGW / Without MW \\
Case 5 & $\begin{array}{l}\text { Without OHGW / With MW } \\
\text { (common grounding of MW and NW) }\end{array}$ \\
\hline Case 6 & $\begin{array}{l}\text { Without OHGW / With MW } \\
\text { (separate grounding of MW and NW) }\end{array}$ \\
\hline
\end{tabular}

currently account for the MW. If the effect of the MW is taken into consideration, then the lightning protection system in relation to the economics can be established. Therefore, we set the simulation conditions in this paper as described in Table 3 in order to analyze the effects of the MW in the distribution line without OHGW.

In case 2, 3 and 5 and 6 , the common or separate groundings of the MW and NW were compared in order to determine the grounding method of the MW and NW. For each case in Table 3, direct and indirect lightning strikes were simulated. In the case of direct lightning, lightning magnitudes of $4.4[\mathrm{kA}], 10[\mathrm{kA}]$, and $30[\mathrm{kA}]$ were simulated, while lightning magnitudes of $20[\mathrm{kA}], 50[\mathrm{kA}]$, and 100 [kA] were simulated in the case of indirect lightning. The flashover by direct lightning may be occurred by low discharge current, while the possibility of flashover by indirect lightning is high at high discharge current. Therefore, the lightning magnitudes are set differently according to the lightning type. The $100[\mathrm{kA}]$ is applied as maximum lightning magnitude to simulate the flashover by indirect lightning as worst case. Ground resistivity values of $100[\Omega \cdot \mathrm{m}]$ and $300[\Omega \cdot \mathrm{m}]$ were simulated for both direct and indirect lightning.

The lightning locations are marked in Fig. 7. The meanings of lightning locations taken into consideration were as follows:

(1) Pole where the grounding resistance of OHGW was $50[\Omega]$ and a lightning arrester was installed;

(2) Pole where the grounding resistance of OHGW was $300[\Omega]$ and a lightning arrester was not installed; and

(3) Pole where the grounding resistance of OHGW was $50[\Omega]$ and a lightning arrester was not installed.

In simulation of direct lightning, we did not consider the shielding effect for worst case simulation. In case of indirect lightning, the distance between distribution line and lightning location is determined by striking distance $y_{\min }$ calculated by (12) [14]. Because each lightning event has a different magnitudes, the striking distance is different in each lightning event.

$$
y_{\min }=\sqrt{r_{s}^{2}-\left(r_{g}-h\right)^{2}}
$$

where

$$
\begin{aligned}
& r_{s}: \text { striking distance to overhead line }\left(r_{s}=10 I_{P}^{0.65}\right)[\mathrm{m}] \\
& r_{g}: \text { striking distance to ground }\left(r_{g}=0.9 r_{s}\right)[\mathrm{m}] \\
& h: \text { height of distribution line }[\mathrm{m}]
\end{aligned}
$$

The flashover voltages of line post insulator and suspension insulator are $180[\mathrm{kV}]$ and $230[\mathrm{kV}]$, respectively. The low flashover voltage, i.e. $180[\mathrm{kV}]$, is used at analysis of simulation results for worst case.

\subsection{Simulation results of direct lightning}

Fig. 9 shows the simulation results of direct lightning when the lightning magnitude was $4.4[\mathrm{kA}]$ and the ground resistivity was $100[\Omega \cdot \mathrm{m}]$. Case 1 and Case 2 had the smallest overvoltage regardless of the lightning location. The overvoltage values of case 1 and 2 are very similar. In lightning location (2) and (3) of case 4 and 6, the flashover is occurred, but it does not occurred at case 1, 2, 3, and 5 . Figs. 10 and 11 show the simulation results of direct lightning when the lightning magnitude was $10[\mathrm{kA}]$ and 30 [kA], respectively. Except for lightning location (1), the flashover is occurred at all of cases due to high lightning current. When the installation conditions of the OHGW and MW were equal, lightning location (1) had the smallest overvoltage. This result was due to the existence of the lightning arrester at lightning location (1). If we compared the lightning at the pole without the lightning arrester, i.e.,

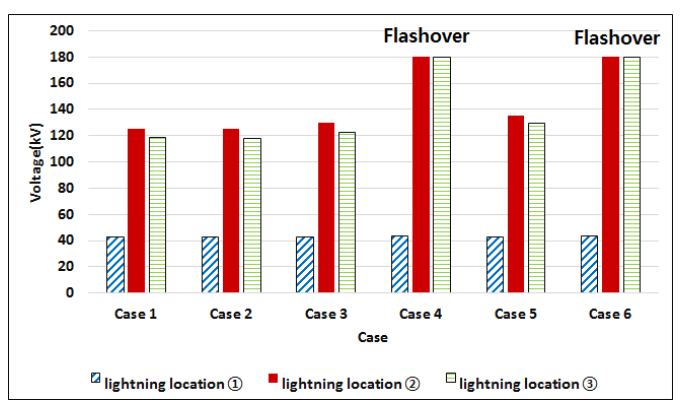

Fig. 9. Simulation results for direct lightning when the lightning magnitude was $4.4 \mathrm{kA}$ and the ground resistivity was $100 \Omega \cdot \mathrm{m}$

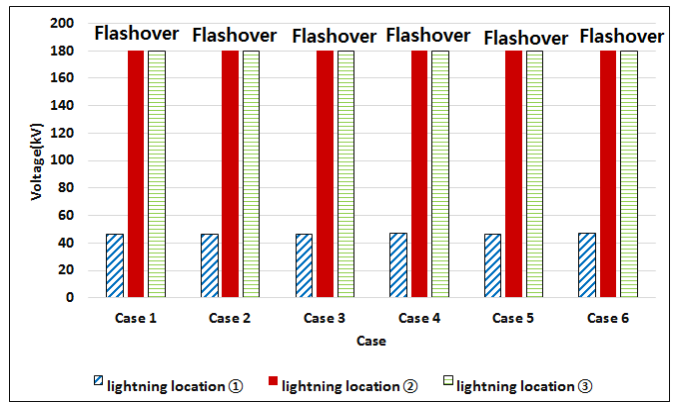

Fig. 10. Simulation results for direct lightning when the lightning magnitude was $10 \mathrm{kA}$ and the ground resistivity was $100 \Omega \cdot m$ 


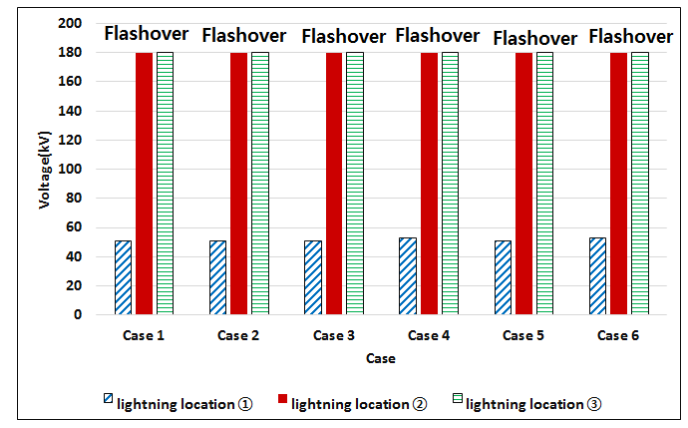

Fig. 11. Simulation results for direct lightning when the lightning magnitude was $30 \mathrm{kA}$ and the ground resistivity was $100 \Omega \cdot m$

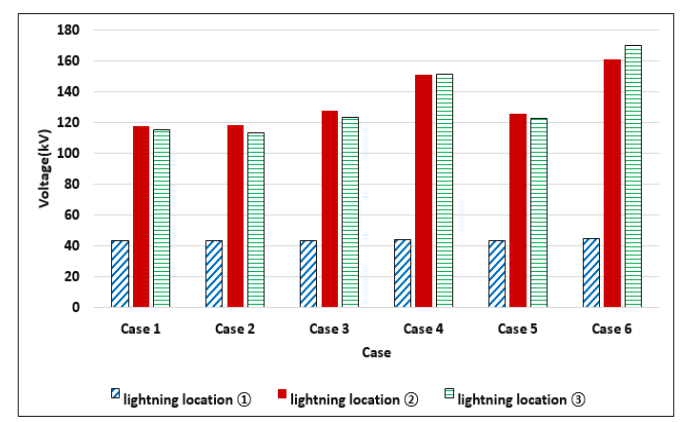

Fig. 13. Simulation results for indirect lightning when the lightning magnitude was $50 \mathrm{kA}$ and the ground resistivity was $100 \Omega \cdot \mathrm{m}$

lightning locations (2) and (3), the lower grounding resistance of the OHGW led to the smaller overvoltage.

Although this paper does not include the simulation results when the ground resistivity was $300[\Omega \cdot \mathrm{m}]$, the tendency of the simulation results indicates that it would be equal to that when the ground resistivity was $100[\Omega \cdot \mathrm{m}]$.

\subsection{Simulation results of indirect lightning}

Figs. 12, 13, and 14 show the simulation results for indirect lightning when the lightning magnitude was 20 $[\mathrm{kA}], 50[\mathrm{kA}]$, and $100[\mathrm{kA}]$, respectively, and the ground resistivity was $100[\Omega \cdot \mathrm{m}]$. From Fig. 12 and 13 , we can find that the induced voltage in case 1, 2, 3 and 5 is lower than the one in case 4 and 6 at all of lightning locations. In Fig. 14 , the flashover is occurred except for lightning location (1).

\subsection{Discussion}

We simulated both direct and indirect lightning. Regardless of the lightning magnitude, lightning location, and ground resistivity, the ascending order of the lightning overvoltage by direct and indirect lightning according to the installation conditions of the $\mathrm{OHGW}$ and $\mathrm{MW}$ was as follows:

(1) Case 1: With OHGW / Without MW,

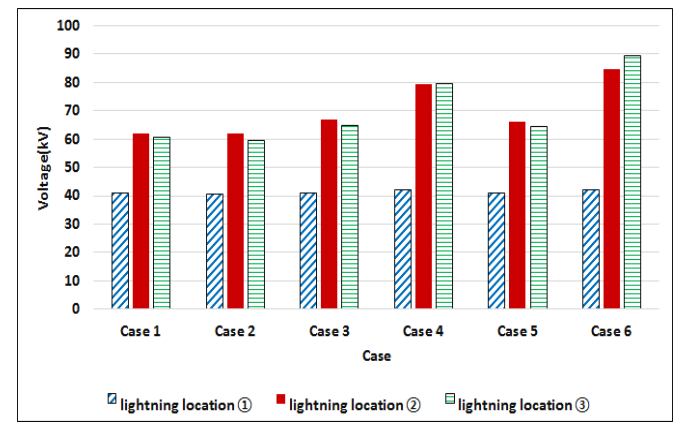

Fig. 12. Simulation results for indirect lightning when the lightning magnitude was $20 \mathrm{kA}$ and the ground resistivity was $100 \Omega \cdot \mathrm{m}$

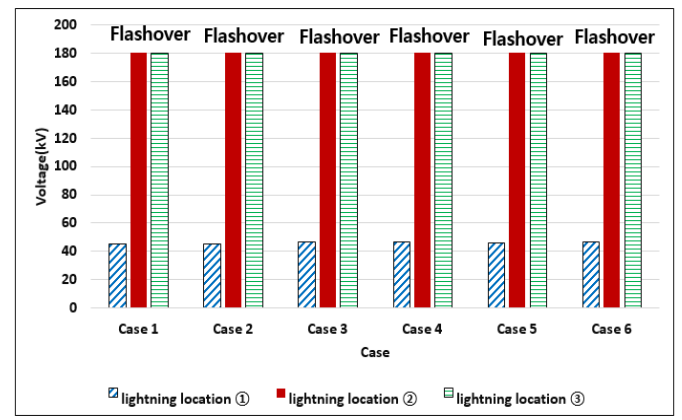

Fig. 14 Simulation results for indirect lightning when the lightning magnitude was $100 \mathrm{kA}$ and the ground resistivity was $100 \Omega \cdot \mathrm{m}$

= Case 2: With OHGW / With MW (common grounding of MW and NW),

(2) Case 3: With OHGW / With MW (separate grounding of MW and NW),

(3) Case 5: Without OHGW / With MW (common grounding of $\mathrm{MW}$ and $\mathrm{NW}$ ),

(4) Case 4: Without OHGW / Without MW, and

(5) Case 6: Without OHGW / With MW (separate grounding of $\mathrm{MW}$ and $\mathrm{NW}$ ).

The overvoltage values in cases with OHGW are lower than cases without OHGW. The difference of overvoltage between case 1, 2, and 3 is very small. Here, we focus on case 5. From Figs. 9, 12, and 13, we can find that the difference of overvoltage between case 3 and 5 is small. However, the one between case 5 and 4 is over $15[\mathrm{kV}]$ in Fig. 12 and $30[\mathrm{kV}]$ in Fig. 13.

Table 4 and 5 show the occurrence of flashover at all of simulation cases. ' $O$ ' means that flashover is occurred, while ' $\mathrm{X}$ ' means that flashover is not occurred. In case of direct lightning with $4.4[\mathrm{kA}]$, the flashover is not occurred at case 1,2,3, and 5, however, the flashover is occurred at case 4 and 6 . At another simulation cases, the occurrence or not of flashover is equal.

From these discussions, we can find that if the MW with common grounding with $\mathrm{NW}$ is installed in distribution line without $\mathrm{OHGW}$, the lightning overvoltage is nearly 
Table 4. Occurrence of flashover at each case in case of direct lightning

\begin{tabular}{|c|c|c|c|c|c|c|c|c|c|}
\hline \multirow[b]{2}{*}{ Case } & \multicolumn{3}{|c|}{$\begin{array}{c}\text { Lightning } \\
\text { location (1) }[\mathrm{kA}]\end{array}$} & \multicolumn{3}{|c|}{$\begin{array}{c}\text { Lightning } \\
\text { location (2) }[\mathrm{kA}]\end{array}$} & \multicolumn{3}{|c|}{$\begin{array}{c}\text { Lightning } \\
\text { location (3) }[\mathrm{kA}]\end{array}$} \\
\hline & 4.4 & 10 & 30 & 4.4 & 10 & 30 & 4.4 & 10 & 30 \\
\hline Case 1 & $x$ & $x$ & $x$ & $x$ & 0 & 0 & $x$ & 0 & 0 \\
\hline Case 2 & $x$ & $x$ & $x$ & $x$ & 0 & 0 & $x$ & 0 & 0 \\
\hline Case 3 & x & $x$ & $x$ & $\bar{x}$ & 0 & 0 & $x$ & 0 & 0 \\
\hline Case 4 & $x$ & $x$ & $x$ & 0 & 0 & 0 & 0 & 0 & 0 \\
\hline Case 5 & $x$ & $x$ & $x$ & $\times$ & 0 & 0 & $x$ & 0 & 0 \\
\hline Case 6 & $x$ & $x$ & $x$ & 0 & 0 & 0 & 0 & 0 & 0 \\
\hline
\end{tabular}

Table 5. Occurrence of flashover at each case in case of indirect lightning

\begin{tabular}{|c|c|c|c|c|c|c|c|c|c|}
\hline \multirow[b]{2}{*}{ Case } & \multicolumn{3}{|c|}{$\begin{array}{c}\text { Lightning } \\
\text { location (1) }[\mathrm{kA}]\end{array}$} & \multicolumn{3}{|c|}{$\begin{array}{c}\text { Lightning } \\
\text { location (2) }[\mathrm{kA}]\end{array}$} & \multicolumn{3}{|c|}{$\begin{array}{c}\text { Lightning } \\
\text { Location (3) }[\mathrm{kA}]\end{array}$} \\
\hline & 20 & 50 & 100 & 20 & 50 & 100 & 20 & 50 & 100 \\
\hline Case 1 & $x$ & $x$ & $\bigcirc$ & $x$ & $x$ & 0 & $x$ & $x$ & 0 \\
\hline Case 2 & $\times$ & $\times$ & 0 & $\times$ & $x$ & $\bigcirc$ & $x$ & $x$ & 0 \\
\hline Case 3 & $x$ & $x$ & 0 & $x$ & $x$ & 0 & $x$ & $x$ & 0 \\
\hline Case 4 & $x$ & $\times$ & 0 & $x$ & $\times$ & $\bigcirc$ & $x$ & $x$ & 0 \\
\hline Case 5 & $\times$ & $x$ & 0 & $x$ & $\times$ & 0 & $x$ & $x$ & 0 \\
\hline Case 6 & $x$ & $x$ & $\bigcirc$ & $x$ & $\times$ & $\bigcirc$ & $x$ & $x$ & 0 \\
\hline
\end{tabular}

equal in case of distribution line with OHGW. In other words, although the OHGW does not exist, the lightning performance can be maintained by installation of MW with common grounding with NW.

Therefore, we can conclude that the MW can be applicable as purpose of lightning protection as well as natural purpose.

\section{Conclusion}

The MW is a wire or cable used for the physical support of another element. This paper proposes the applicability of MW as a purpose of lightning protection. To verify this possibility, we perform the theoretical analysis of overvoltage considering $\mathrm{MW}$ and simulate the lightning overvoltage according to the installation conditions of OHGW and MW in the Korean distribution system. From the simulation results, we can find that when the OHGW was not installed but the MW with common grounding with NW was installed, the overvoltage could be reduced due to the common grounding and hence the occurrence possibility of flashover can be reduced. Therefore, this paper can conclude that if the MW was installed and the OHGW was removed from the distribution line for which the probability of direct lightning was low, the lightning protection system could be maintained by the common grounding of the MW and NW, i.e. the MW can be applicable as a new purpose of lightning protection.

$\mathrm{GW}$ has a function of reducing electromagnetic field besides lightning protection function. This paper proposes the applicability of MW only focusing on lightning protection function of OHGW. To perfectly replace the OHGW to MW, the several points of view such as reducing electromagnetic field, economics, and etc. must be considered.

\section{References}

[1] Keon-Woo Park, Hun-Chul Seo, Chul-Hwan Kim, Chang-Soo Jung, Yeon-Pyo Yoo, Yong-Hoon Lim, "Analysis of the Neutral Current for Two-Step-Type Poles in Distribution Lines", IEEE Transactions on Power Delivery, Vol. 24, No. 3, pp. 1483-1489, July 2009.

[2] W. A. Chisholm, K.L. Cummins, K.L, "Lightning protection of Smart Grid components", International Symposium on Lightning Protection 2011, October 37, 2011.

[3] Mario Paolone, Carlo Alberto Nucci, Emanuel Petrache, and Farhad Rachidi, "Mitigation of Lightning-Induced Overvoltages in Medium Voltage Distribution Lines by Means of Periodical Grounding of Shielding Wires and of Surge Arresters: Modeling and Experimental Validation", IEEE Trans. On Power Delivery, Vol. 19, No. 1, pp. 423-431, January 2004.

[4] Alberto Borghetti, Carlo Alberto Nucci, Mario Paolone, "An Improved Procedure for the Assessment of Overhead Line Indirect Lightning Performance and Its Comparison with the IEEE Std. 1410 Method", IEEE Transactions on Power Delivery, Vol. 22, No. 1, pp. 684-692, January 2007.

[5] S. Yokoyama, K. Yamamoto, and H. Kinoshita, "Analogue simulation of lightning induced voltages and its application for analysis of overhead-groundwire effects," Proc. Inst. Elect. Eng., vol. 132, no. C4, pp. 208-216, 1985.

[6] V. Rakov and F. Rachidi, "Overview of recent progress in lightning research and lightning protection", IEEE Trans. on Electromagnetic Compatibility, vol. 51, no. 3, pp. 428-442, Aug. 2009.

[7] CRIEPI, "Guide of Lightning Protection Design for Power Distribution Lines", JAPAN, 2002.

[8] Ametani, T. Kawamura, "A Method of a Lightning Surge Analysis Recommended in Japan using EMTP", IEEE Trans. On Power Delivery, Vol. 20, No. 2, pp. 867-875, April 2005.

[9] H. Motoyama, Y. Kinoshita, and K. Nonaka, "Experimental study on lightning surge response of $500-\mathrm{kV}$ transmission tower with overhead lines", IEEE Trans. Power Delivery, vol. 23, no. 4, pp. 2488-2495, Oct. 2008.

[10] Hun-Chul Seo, Chul-Hwan Kim, "Analysis of Stability of PV System using the Eigenvalue according to the Frequency Variation and Requirements of Frequency Protection", Journal of Electrical Engineering \& Technology. Vol. 7, no. 4, pp. 480-485, July 2012. 
[11 In-Soo Kim, Woong Han, Sang-Min Yeo, Chul-Hwan Kim, Bong-Ju Weon, Yong-Hun Lim, "A Study on Shielding Effect of the Messenger Wires in Distribution Lines", Trans. KIEE, Vol. 58, No. 3, pp. 431-436, Mar 2009.

[12] C. A. Jordan, "Lightning computations for transmission lines with overhead ground wires, Part II," Gen. Electr. Rev., vol. 37, no. 4, pp. 180-186, 1934.

[13] Alberto De Conti, Silv'erio Visacro, Amilton Soares, Jr., Marco Aur'elio Schroeder, "Revision, Extension, and Validation of Jordan's Formula to Calculate the Surge Impedance of Vertical Conductor", IEEE Trans. on Electromagnetic Compatibility, Vol. 48, No. 3, August 2006.

[14] "Guide for improving the lightning performance of electric power overhead distribution lines", IEEE Std 1410, 2010, IEEE Working Group on the lightning performance of distribution lines.

[15] F. Heidler, J. M. Cvetic, and B. V. Stantic, "Calculation of lightning current parameters", IEEE Trans. On Power Delivery, vol. 14, no. 2, pp. 399-404, Apr. 1999.

[16] Hans Kristian Hoidalen, "Analytical Formulation of Lightning-Induced Voltages on Multiconductor Overhead Lines Above Lossy Ground", IEEE Transactions on Electromagnetic Compatibility, Vol. 45, No. 1, pp. 92-100, February 2003.

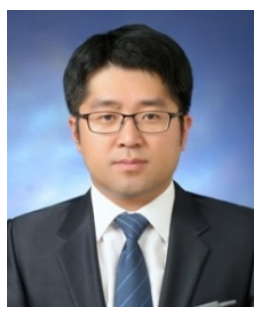

Hun-Chul Seo He received his B.S, M.S, and Ph. D. degrees from Sungkyunkwan University, Korea, 2004, 2006, and 2013, respectively. He worked for Korea Electrical Engineering \& Science Institute, Seoul, Korea, as a researcher in power system division from 2006 to 2009. He was a postdoctoral fellow in the dept. of electrical engineering, Yeungnam University, Korea, from Sep. 2013 to Jan. 2014. From Mar. 2014, he is an assistant professor with the School of IT Engineering at Yonam Institute of Digital Technology, Korea. His research interests include power system transients, protection and stability.

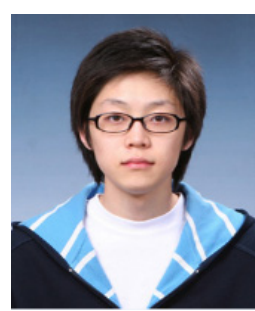

Joon Han He received his B.S degree in School of Electrical Engineering from Soonchunhyang University, Korea, 2011 and M.S degree in College of Information and Communication Engineering from Sungkyunkwan University, Korea, 2013. At present, he is working on his Ph. D thesis at Sungkyunkwan University. His research interests include power system transients, protection and DC distribution system.

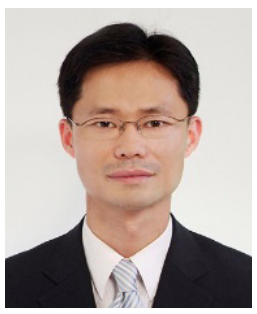

Sun-Kyu Choi He received his B.S and M.S degrees in School of Electrical Engineering from Korea University, Korea, 2000 and 2002. He has been with KEPRI, KEPCO, as a member of the researcher since 2003. His special fields of interest are a grounding method, lightning protection and power quality of distribution system.

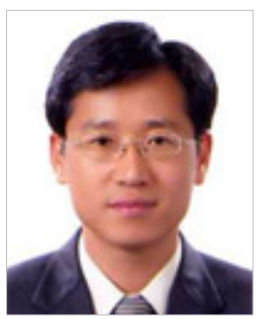

Byung-Sung Lee $\mathrm{He}$ received his Ph.D from Chungnam National University in 2006 in high voltage engineering. He has been with KEPRI, $\mathrm{KEPCO}$, as a member of the researcher since 1995. His special fields of interest are the intelligent distribution automation system, RCM of distribution facilities and lightning protection, and the lifetime estimation of distribution equipments.

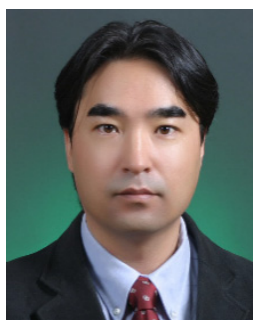

Sang-Bong Rhee He received his B.S, M.S, and Ph.D. degrees from Hanyang University, Korea, in 1994, 1999, and 2004, respectively. He was a research professor in the School of Electrical and Computer Engineering, Sungkyunkwan University, Korea. Currently, he is an assistant professor with the dept. of electrical engineering at Yeungnam University, Korea. His research interests include a distribution system control and operation, and artificial intelligence applications to power system protection.

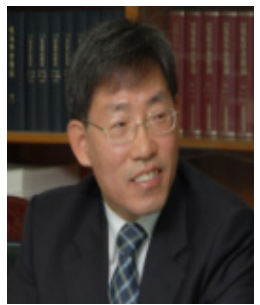

Chul-Hwan Kim In 1990 he joined Cheju National University, Cheju, Korea, as a full-time Lecturer. He has been a visiting academic at the University of BATH, UK, in 1996, 1998, and 1999. Since March 1992, he has been a professor in the School of Electrical and Computer Engineering, Sungkyunkwan University, Korea. His research interests include power system protection, artificial intelligence application for protection and control, the modeling / protection of underground cable and EMTP software. He received his B.S and M.S degrees in Electrical Engineering from Sungkyunkwan University, Korea, 1982 and 1984, respectively. He received a $\mathrm{Ph} . \mathrm{D}$ in Electrical Engineering from Sungkyunkwan University in 1990. Currently, he is a director of Center for Power IT(CPIT) in Sungkyunkwan University. 